\title{
De Aficiones, Rituales y Mundos de ARTe: un ANÁlisis de UN PROCESO de CREACIÓn Colectiva Popular
}

\author{
Nicolás Aliano ${ }^{1}$ \\ Universidad Nacional de La Plata, Buenos Aires, Argentina
}

\begin{abstract}
Como parte de una investigación sobre aficionados de un músico popular argentino, el artículo analiza una dimensión especifica de una de sus prácticas de afición. La indagación aborda el trabajo de producción de banderas que una parte del público realiza para presentar en los recitales de este artista. En esta clave, reconstruir el circuito de usos de un objeto-las banderas-nos ha conducido hacia la red colaborativa en la que se constituye, visibilizando un "mundo de arte" popular en torno a la música. Se trata de una red colectiva "en bambalinas" que las hace posible como objetos estéticos por derecho propio: una escena anclada en el mundo cotidiano de las personas (y que por ello se vale de los recursos, y relaciones disponibles en ese mundo), que a la vez se co-produce en interacción con el momento ritual del recital, resultando fundamental para sustentarlo como tal. Visibilizar a estos "bacedores de banderas" populares tiene como objetivo iluminar una posibilidad analítica escasamente tematizada: presenta un "mundo del arte" popular no profesionalizado ni sostenido en instituciones formales, sino más bien en una red de prácticas colectivas informales y una economia moral que hacen posible su continuidad. La indagación, en consecuencia, abre una senda a complejizar los análisis de los procesos de creación artística colectiva en el mundo popular y destaca los efectos sociales y politicos de esas prácticas sobre la propia experiencia cotidiana de los fans.

Palabras clave: arte popular, redes de colaboración, aficionados a la música, prácticas de ritualización, creación artística colectiva
\end{abstract}

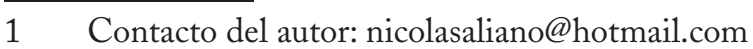




\section{INTRODUCCIÓN}

Este artículo forma parte de una investigación sobre prácticas de afición en torno a un músico popular argentino, el cantante de rock Carlos "Indio" Solari. ${ }^{2}$ En Argentina, los recitales de este artista se han tornado eventos multitudinarios, nutridos por un público heterogéneo que abarca varias generaciones y estratos sociales. Como emergente de un proceso que se prolonga desde mediados de la década de los noventa hasta la actualidad, la figura de Solari se ha vuelto un objeto de culto y los recitales eje de una creciente ritualización ${ }^{3}$, siendo el fenómeno particularmente gravitante en ciertas capas del mundo popular contemporáneo.

En este marco, una de las prácticas de ritualización (Bell 1992) que contribuye a crear el contexto festivo de los recitales y la "previa" a los mismos, es la realización de banderas y su exhibición frente a otros aficionados. Estas banderas son producciones que suelen combinar una frase tomada de las letras de las canciones, junto a imágenes provenientes de la gráfica de los discos o de fotografías difundidas de los músicos. Esos elementos pintados, además suelen ir acompañados con los nombres de las personas que la realizaron, de seres queridos a los que por algún motivo se quiere rendir homenaje, o del barrio de procedencia de los fans. La realización y exhibición de estas banderas constituye una práctica medular en esta escena, aunque no se restringe a ella: la misma ha sido observada también en otros casos ligados al rock nacional, fundamentalmente en su vertiente "barrial" o "chabón" (Salerno y Silba 2006; Semán 2006; Alabarces 2008; Benedetti 2008). Se trata de una práctica compleja en su sentido geertziano: la misma reúne múltiples dimensiones, conecta con universos simbólicos próximos -como el de las hinchadas de futbol- y condensa diversos sentidos sociales.

En trabajos anteriores (Aliano et al 2010; Aliano 2015) se han recuperado algunas de estas dimensiones, fundamentalmente aquellas asociadas a sus usos en el contexto del recital y al arco de relatos que se abren al momento de "explicar" las banderas y con ello la propia vivencia de la afición. Estos análisis permitieron recuperar facetas de la experiencia cotidiana de estas personas, que inscriptas simbólicamente en las banderas, "llevaban" al momento extraordinario del recital. En este marco, asimismo, en un trabajo reciente (Aliano 2018) se ha profundizado en una de las significaciones de esta práctica, aquella referida al carácter terapéutico que asume la música en general y la elaboración de estas "banderas" para una parte del público en particular. Es a través de ellas que estos aficionados procesan simbólicamente diversas experiencias de aflicción y sufrimiento, al tiempo que sacralizan la práctica y la escena.

El presente artículo procura abordar una dimensión menos explorada de esta práctica, que sin embargo permite visibilizar y reconstruir un universo sociocultural complejo, captando los entramados sociales en los que las prácticas artísticas se modelan y constituyen, en tanto "red de colaboraciones", en términos de Becker (2008). Aquí se propone analizar el trabajo de "producción" de estas banderas, la escena colectiva en bambalinas que las hace posible como objetos estéticos por derecho propio: una escena colaborativa anclada en el mundo cotidiano de las personas, pero fundamental para elaborar la afición y sustentar la escena colectiva extraordinaria más amplia.

2 Aliano (2015). Esta investigación ha sido financiada por una beca doctoral otorgada por el Consejo Nacional de Investigaciones Científicas y Técnicas (CONICET).

3 Un indicador de este componente de ritualización presente en los recitales se puede encontrar en una de las definiciones nativas con las que se los suele aludir, como "misas paganas”. 
Con ello, el artículo presenta un análisis situado en la convergencia de dos campos que se han desarrollado separadamente: por un lado, se inscribe en los debates sobre procesos de "ritualización": una serie de análisis que conciben al ritual como una perspectiva para el estudio de situaciones sociales, más que como algo definible por un conjunto de rasgos absolutos (Bell 1997; Da Matta 2002; Peirano 2000). Desde este giro esta literatura propone un acercamiento al ritual que tenga en cuenta los modos en que cada comunidad "ritualiza" a partir de mecanismos sociales diversos. Por otro lado, el análisis se inscribe en los estudios asociados a la sociología del trabajo artístico inaugurada por Howard Becker: una perspectiva ligada a lo que Benzecry (2012a) denomina en términos más amplios como "enfoque de producción de la cultura".

En esta doble vía el caso muestra que, como en la figura de las muñecas rusas que se encastran unas en otras, la escena del recital masivo (que se recrea una y otra vez con cada show como ritual extraordinario que produce un hecho "cultual") contiene otras escenas que forman parte de un "mundo del arte" anclado en lo cotidiano, que elabora "desde abajo" las prácticas de ritualización actualizadas en cada show, al tiempo que produce sus propios objetos artísticos. De modo que el caso de estos "hacedores de banderas" populares ilumina una posibilidad analítica escasamente problematizada. El mismo da cuenta de un "mundo del arte" popular no institucionalizado ni anclado en instituciones oficiales: una posibilidad que, si bien contemplada por Becker, ha sido escasamente analizada en estudios empíricos ${ }^{4}$, y abre por ello una senda a complejizar los análisis de los procesos de creación artística colectiva, al tiempo que destacar sus efectos sociales. En este sentido, aquí se subraya el carácter colaborativo (y a la vez no intencionado) de los procesos de producción de un "mundo de arte" sustentado en una red de prácticas colectivas informales y una economía moral que hacen posible su continuidad.

La estrategia metodológica que orienta este análisis, de tipo cualitativo, estuvo basada en seguir un objeto-práctica en su circuito de producción-circulación, partiendo del recital como escena en la que se visibilizaron y contactaron a estos aficionados. En este cuadro, se planteo una estrategia de problematización de la escena que desplazara el foco "del recital" hacia las diversas escenas cotidianas de ejercicio y elaboración de la afición. El trabajo de campo incluyó entrevistas informales y en profundidad, así como experiencias de observación participante y análisis discursivo de material gráfico y textual producido por los fans. ${ }^{5}$

\footnotetext{
4 En este cuadro, cabe señalar que si bien otros trabajos ya han abordado, siguiendo la perspectiva de Becker, la configuración de diversos "mundos del arte" asociados a consumos populares -tales como los "mundos del cuarteto" (Blázquez, 2009) o más recientemente los "mundos del animé” (Díaz, 2019)-, estas indagaciones se han enfocado en analizar mundos profesionalizados o, en todo caso, su proceso de profesionalización. En este punto, el "mundo" de los hacedores de banderas abordado aquí, preserva una especificidad que lo diferencia de estos casos: su carácter no profesionalizado. Asimismo, este trabajo se inscribe en una agenda reciente más amplia y en desarrollo, en torno al estudio de aficionados a diversos objetos de la cultura popular y masiva. En términos generales, estas exploraciones convergen en destacar el rol activo de los públicos en la producción de sentido. Para un recorrido por esta literatura el lector puede remitirse a: Borda, 2011.

5 El trabajo de campo, de tipo etnográfico, se llevó a cabo entre 2009-2014, en el marco de mi investigación doctoral. Parte del trabajo de campo presentado aquí ha sido realizado junto a Mariana López, Nicolás Welschinger y Jerónimo Pinedo, a quienes agradezco especialmente por compartir el material. El mismo tuvo su origen en el marco del Proyecto de investigación colectivo "Los géneros musicales populares: producción, circulación y recepción. Identidades sociales y música entre los jóvenes del Gran Buenos Aires”, dirigido por Pablo Semán y financiado por la Agencia Nacional de Promoción Científica y Tecnológica.
} 


\section{LAS BANDERAS EN EL RECITAL: USOS, EXPECTATIVAS Y CONVENCIONES}

Las banderas o "trapos" se elaboran para exhibirse tanto durante el show como en sus momentos previos. En este sentido, para los seguidores, el recital no puede escindirse del momento que se desenvuelve como su preparación. Este periodo precedente es referido como "la previa" y forma parte de la escena ampliada del recital masivo de música rock (Aliano, et al 2010). La previa se va conformando como un contexto festivo, modulado por la presencia de música, cánticos, y rondas de personas reunidas. Se trata de una escena que se va constituyendo en las inmediaciones del predio donde se presentará el artista.

En este contexto, las banderas ocupan un lugar central para circunscribir el espacio que van ocupando cada uno de los grupos de fans. Extendidas sobre el piso, amarradas entre árboles o colocadas sobre algún vehículo o alguna pared, se disponen de manera que adquieran visibilidad, y en torno a ellas se organiza el grupo (ver imagen 1). En este marco, asimismo, los fans deambulan observando las banderas de otros seguidores, y algunos de ellos piden "sacarse fotos" junto a algún "trapo" que captó la atención. Esta acción se vuelve un catalizador de encuentros e intercambios entre desconocidos, y es motivo de orgullo para la persona o el grupo portador de la bandera, que suele percibir en ello un gesto de reconocimiento por el trabajo realizado.

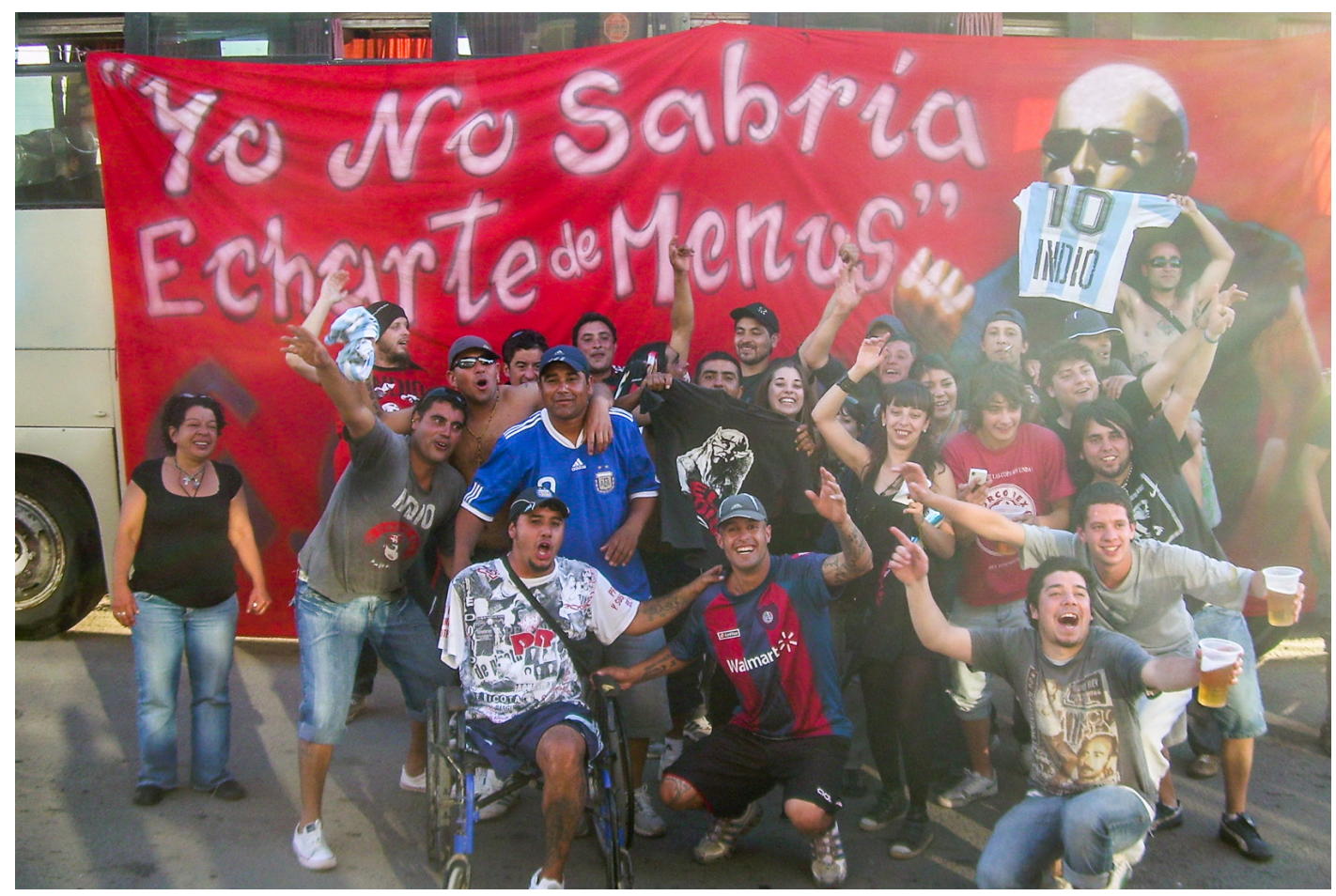

Imagen 1. "Yo no sabría echarte de menos" (Tandil, 2010). Fotografía del autor.

En estos usos se advierten ciertas expectativas convencionalizadas, tanto del papel de las banderas en la "previa" como durante el recital y frente al artista (hay momentos precisos del show como ejecución de la canción Juguetes perdidos ${ }^{6}$ donde las banderas ganan protagonismo y deben ser flameadas o señaladas). Los lugares donde deben exhibirse antes y después del recital,

6 Esta canción es una de las “clásicas” del repertorio de Solari (perteneciente a su ex banda Patricio Rey), y esta invariablemente presente en sus shows. Sus primeros versos refieren: "Banderas en tu corazón,

yo quiero verlas! / Banderas rojas! Banderas negras! / de lienzo blanco en tu corazón.” 
las reacciones del público general hacia ellas (sacarle fotos, por ejemplo) y de sus dueños (exponer con orgullo su producción), los modos de ser llevadas y expuestas o las búsquedas por ser "nombradas" desde el escenario, se encuentran dentro de un horizonte de expectativas (Kosselleck 1993; Cardoso Filho y de Oliveira 2013) 7 más o menos estabilizado. Se trata de un ajuste entre las expectativas esperadas y las experiencias sedimentadas, que da cuenta de un modo estabilizado de ser un seguidor comprometido y apasionado y de la conformación de esta práctica como una convención de la escena. Esta "inercia” (Becker 2009) de la escena es aprendida por los neófitos que, al momento de hacer una bandera, ya conocen parcialmente cómo se regula la práctica.

En este sentido, la elaboración de "banderas" para llevar al recital no deja de ser una producción regulada, con cierta estética y cierto código de uso: las elecciones sobre los motivos y diseños, sobre los modos de presentación y valoración, encuentra una regulación -flexible- pero que no es ajena a quienes la realizan. Así, quien toma la decisión de realizar una bandera, por lo general ha transitado por una serie de pasos: (1) ha incorporado previamente el código de su uso a partir de la asistencia a recitales pasados, (2) asumió el contrato de escucha propuesto entre público y artista (que involucra la participación activa del mismo), y (3) orienta sus expectativas de acuerdo al mismo.

En este cuadro, la elaboración de banderas para asistir a los shows le permite a ciertos fans exhibir su apego diferenciado y comprometido con esta propuesta musical, "presentándose" públicamente al resto de los asistentes y depositando una expectativa de "reconocimiento" en ello. A su vez, entre este público se dan una serie de expectativas estandarizadas en torno a lo que se espera del show. Estos aficionados, como los fanáticos de la Opera descriptos por Benzecry (2012b), han aprendido a comportarse como tales y han construido un sistema más o menos informal y duradero de disposiciones y apreciaciones en torno al espectáculo. Quienes realizan banderas exhiben un conocimiento de la tradición, hacen una selección de motivos de la misma, incorporaron el código de uso y lo reproducen. Así, la elaboración de banderas es una práctica "regulada" que contribuye, entre otras cosas, a diferenciarse del resto del público y a vivir de una manera intensa el show. Sin embargo, ¿cómo han llegado estos fans a presentar esas banderas en el recital? ¿Qué recursos, saberes y relaciones han desplegado para realizar ese objeto-significante? Y en términos más amplios: ¿cómo han "producido" previamente eso que in situ es experimentado como una fiesta que excede todo cálculo y planificación? Responder esas preguntas implica situarnos más acá del recital, y reconstruir el mundo de prácticas colectivas ancladas en la experiencia cotidiana, que posibilitan la afición y la presencia. En este sentido, como afirma Antoine Hennion, "la inmediatez es el resultado paradójico de una extensa secuencia de mediaciones" (2012: 236).

$7 \quad$ La categoría de "horizonte de expectativas", inicialmente aplicada por Jauss (1992) a los estudios literarios y por Reinhart Kosselleck (1993) al análisis histórico, pone de relieve la relación entre expectativas y experiencias. Cardoso Filho y de Oliveira (2013) subrayan la pertinencia de dicha categoría para el análisis de escenas musicales: "Se trata, de acuerdo a nuestra comprensión, de una demostración que se establece entre experiencia estética, sincronía y diacronía -exactamente la naturaleza de problema de aquellos que se ocupan de reunir indicios de las escenas musicales para inferir las transformaciones producidas" (2013: 10-11, traducción propia). Para un mayor desarrollo del carácter convencionalizado de esta escena, y de la existencia de una serie de convenciones en torno a los modos de elaborar y presentar las banderas -que dan cuenta de la "inercia" de este mundo- el lector puede remitirse a: Aliano, 2015. 


\section{LAS BANDERAS EN SU PRODUCCIÓN: UN "MUNDO DE ARTE POPULAR"}

Me enfocaré aquí en mostrar que esta "producción de la fiesta" como escena en bastidores, conforma un mundo de arte (Becker 2008) que sostiene la escena del recital extendiéndose infinitesimalmente a través de los contextos familiares, hogareños y barriales, como una red de colaboraciones que dan lugar a producciones estéticas propias y a la estabilización de patrones de organización que hacen posible la asistencia a los recitales. De este modo, se describirá la producción de las banderas y la organización de los viajes como prácticas que, situadas más acá del recital, son sustentadas por soportes colectivos anclados en la experiencia cotidiana, que posibilitan la afición y la presencia.

Al centrarnos en la dimensión de la "producción" de las banderas, se advierte que las mismas ocupan un lugar central en el entramado de prácticas que, con centro en el espacio barrial y familiar de los fans, conforman las redes que luego asisten al recital. En esta preparación no intervienen exclusivamente los fans, sino que se involucran, como parte de un sistema de soportes relacionales que intervienen activamente, a amigos, vecinos, familiares y parejas que contribuyen de diversas formas a la elaboración de las banderas.

Esta participación, como se ha señalado en otro lado, puede abarcar diversos registros, "desde la contribución material, regalos y préstamos de dinero, donación de materiales como pintura, tela, pinceles, aerosoles, hasta el trabajo de producción simbólica, elección de los diseños, realización de los mismos, selección, elaboración e interpretación de frases poéticas" (Aliano et al 2010: 177). De este modo, esas personas participan, "aportando saberes y competencias específicas, por ejemplo el calcado de un dibujo, la modificación y proporción de su escala, el diseño de una tipología vistosa, la costura reforzada de varios metros de tela" (Aliano et al 2010: 177). Siempre hay algún "profesor de dibujo" o alguna modista o amigo o familiar, que aporta los saberes necesarios para hacer -o contribuir a hacer- las banderas.

En este sentido, se activa una trama de relaciones, saberes y valores que intervienen y hacen posible el objeto final, a ser presentado en el recital. En consecuencia, un conjunto de personas que no asisten necesariamente al recital, sin embargo contribuyen de diversas formas a su preparación. "Todo el barrio ayudó", refiere en esta clave un aficionado: vecinos, tíos, abuelos, padres, niños pequeños que no pueden realizar largos viajes para escuchar al músico, forman parte de esta red extendida.

De modo que podemos comprender, desde el punto de vista de la "producción" de banderas, la configuración de todo un "mundo de arte" en el sentido en el que lo concibe Howard Becker (2008), como red establecida de vínculos cooperativos, y a estos "productores" como "artistas folk". Según Becker, "arte folk" sería "el trabajo que se hace completamente al margen de los mundos de arte profesionales, del trabajo que hace gente común en el transcurso de una vida común, del trabajo cuyos autores o usuarios rara vez piensan en términos de arte" (2008: 285).

Becker utiliza analíticamente el ejemplo de la elaboración hogareña de colchas por parte de mujeres estadounidenses, a fin de dar cuenta de las características de este tipo de "artistas folk", en comparación por ejemplo con los "profesionales integrados" del arte canónico. Al respecto destaca que "Los artistas folk se parecen al arte canónico en un punto: pertenecen a una comunidad bien organizada y producen su trabajo como parte de la misma. Las colcheras, sin embargo, no pertenecen a una comunidad de trabajo o profesional dedicada al arte, sino, 
por el contrario, a una comunidad local conformada por hogares” (2008: 286). Las colcheras, concluye Becker, realizan sus trabajos artísticos "en su condición de integrantes de una familia y de vecinas" (2008: 286).

En igual sentido nuestros "productores de banderas" pertenecen a una comunidad en la cual producen y organizan su trabajo, en tanto integrantes de un grupo de amigos, de un grupo familiar o de vecinos. Pero a la vez -a diferencia de las colcheras de Becker- forman parte de una comunidad "interpretativa" ("ricotera") que selecciona motivos, dibujos, frases, de un repertorio disponible de recursos estéticos (graficas de los discos, liricas de las canciones, etc.). Así, si bien no existen criterios de evaluación estandarizados y generalizados sobre como confeccionar una bandera -como muestra Becker para el caso de las colcheras (que conduce a pautas "locales" y "efímeras" de evaluación del trabajo: una feria local o regional, pero no más allá)-, existiría aquí sin embargo cierto código más o menos extendido de elaboración y evaluación de las producciones. Se halla disponible, en este caso, un repertorio -basto pero no infinito- de recursos compartidos: liricas de donde extraer frases, personajes creados en el arte de tapa de los discos, fotografías icónicas, etcétera, que son reutilizados y apropiados de formas variables.

Así, por ejemplo, seleccionar frases de temas inéditos, o copiar imágenes poco difundidas de los músicos, es un modo de singularizar el trabajo y "ser creativos" ante la posible redundancia. En este sentido, explicando las elecciones que suponía su bandera, un aficionado refería: "La frase [seleccionada para la bandera] es de un tema de los inéditos de Los Redondos ${ }^{8}$. La elegimos porque queríamos algo original, algo que no se vea. Estuvimos mirando fotos de banderas de Córdoba de San Luis, y bueno buscamos algo que no esté. Nos fijamos que esta no la tuviera nadie" El joven concluye: "nos dimos cuenta que mucha gente nos pregunta, que no saben de qué tema es. Y bueno, es única”. Otro aficionado, por su parte, ha elegido para plasmar en la bandera un poster que, para él constituye una rareza: "tengo el póster completo donde están los cinco [integrantes del grupo]; lo agarré y la hice. El poster es del '98, (...) es un póster que lo tengo viejísimo. Lo tengo guardado como una reliquia porque es uno de los últimos que hay de todos juntos".

A su vez, cuando nos enfocamos en los modos de realización, observamos las simetrías con el caso de las "colcheras" analizado por Becker. Por un lado, si atendemos al origen de los materiales con que se confeccionan las banderas, en la mayor parte de los casos da cuenta de la inserción comunitaria de sus productores, que -no valiéndose de medios técnicos específicos o profesionales- apelan a los recursos disponibles en su ámbito próximo, o reutilizando materiales que tenían otros fines utilitarios. Dando cuenta de ello, un aficionado refería:

Estaba en la fábrica trabajando, en Apache, que es una fábrica metalúrgica, y en la ropa de los trapos apareció esta bandera. Es una bandera de mástil, de Argentina. Así que me la llevé. Me la llevé para tapar el auto al principio, y después cuando vi que era grosa la usé para esto.

¿Y cómo llego la bandera a la fábrica?

Llego como trapo, como trapo para cortar y limpiarse las manos. Así que después dije "a esta la tengo que pintar" y después agarre y le mandé letras de la banda... y después le quería pintar a Homero, pero soy medio amargo dibujando, así que le hice la mano con las cadenas nada más. Me llevo mes y medio, dos meses, laburarla. Tres o cuatro horas por día después del laburo... Tiene un laburo de loco, porque además yo no soy pintor, ¿viste? La dibuje con lápiz primero y después le metí pincel.

8 La expresión alude a la banda de rock "Patricio Rey y sus Redonditos de Ricota", liderada por Solari hasta su disolución en 2001. La misma ha sido popularizada como "Los Redondos" por los fans. 
En igual sentido que lo señalado en este relato, otros jóvenes me confesaron que usaron una cortina de la casa para hacer la bandera, y una pareja reutilizó el paño con el cual vendían artesanías para el mismo fin. Asimismo, otro entrevistado me cuenta: "la bandera la compré para el mundial '94, y siempre la llevé a los recitales de Los Redondos, pero sola. Y esta vez la

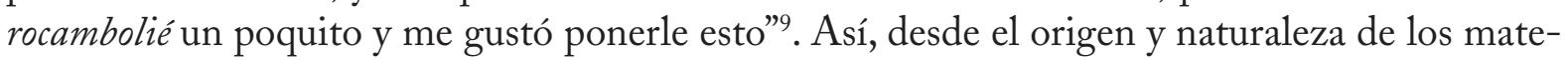
riales disponibles para realizar los trapos se ve la inserción en el mundo práctico y cotidiano de quienes las confeccionan, que apelan a elementos, saberes y competencias de la vida cotidiana y laboral para confeccionar las banderas: elementos que encuentran en el trabajo, o en sus casas, o que compraron con otros fines y reutilizan en este nuevo "proyecto". Esta inserción comunitaria también puede observarse en los usos que se les da a las banderas más allá de la asistencia y exposición en el recital, que se inscriben en diferentes escenarios de la vida cotidiana mencionados recurrentemente: cumpleaños, aniversarios de casamientos, bautismos, celebraciones familiares, campeonatos de futbol vecinales, son todas ocasiones para la exhibición de las banderas, que se suelen tener guardadas en lugares "especiales" o colgadas como un adorno más, generalmente en la habitación.

Por otra parte, al no valerse de medios técnicos específicos ni recursos materiales garantizados por una actividad artística profesional, se apela a diversas estrategias para solventar los necesarios gastos que implica la producción de las banderas. Las mismas van desde el costeo personal de algunos materiales y el lienzo hasta la organización de rifas, colectas, o venta de banderas por encargo para poder afrontar los gastos de la propia. Este último es, por ejemplo, el caso de Cacho, que es costurero y en sus ratos libres hace banderas a pedido. Enseñándome la suya Cacho cuenta: "esta bandera nos llevó un mes, trabajando unas dos horas por día... la pinté con lapicera, no con aerosol, porque así dura más, se puede volver a lavar. Tenía otra y la vendí cuando estaba flojo de moneda".

Observamos, en este sentido, que el modo en el que se obtienen y dispone de recursos tanto materiales como de personal con competencias y saberes específicos (alguien que sepa dibujar o calcar, coser o pintar bien), así como lo que Becker denomina "personal de apoyo" (quien, por ejemplo, una vez diseñada la bandera ayude a "rellenar" las letras o dibujos), conduce también a delinear un tipo de organización específica. Es decir, si la obtención de recursos materiales es problemática, así como asegurarse el tiempo libre necesario para dedicarle (la producción de las banderas, como de cualquier objeto, lleva tiempo, tiempo que se le resta a otras actividades), resulta habitual que los proyectos adopten la forma de colectivos en que "todos contribuyen" de diversas formas al resultado final, distribuyendo y coordinando recursos escasos. En este sentido, como sostiene Becker, "todo patrón de disponibilidad refleja un tipo de organización social y se convierte en parte del patrón de limitaciones y posibilidades que conforman el arte que se produce (2008: 116)". Un entrevistado de un grupo de seguidores describe como hicieron su bandera, y en su relato se plasma muy bien la forma en la que se imbrican recursos (materiales, técnicos, disponibilidad de tiempo, saberes) con modos de organización:

Fuimos el martes. Y el martes arrancamos. Si, un re trabajo de mi amigo Matías que no llegó todavía. El dibujó y nosotros la pintamos. Un poco cada uno. Las letras, las dibujó también un amigo y las pintamos entre todos (...). Fue de común acuerdo. Y después de este lado, queríamos dibujar, y no sabíamos que dibujar. Es el dibujo de la remera de un amigo, que esta con los dibujos de un CD de Los Redondos. Tal cual está el dibujo, impresionante. Y la combinación de colores también se encargó el loco.

9 "Rocambolié" hace referencia al artista plástico Rocambole (Ricardo Cohen), a cargo del diseño gráfico de los discos de la banda. 
Los proyectos siempre adoptan la forma de emprendimientos colectivos en que se distribuyen y coordinan tareas frente a recursos escasos: saberes diversos "el que sabe dibujar", "el que sabe coser", tiempos de trabajo para dedicarle, materiales para la confección (alguien que se dedica a conseguir determinada pintura, alguien más un trozo de lienzo), etcétera. "Tenemos todo sacado [fotografiado] paso a paso", concluye el entrevistado. Y como afirma Becker (2008: 17), finalmente, la obra "siempre revela indicios de esa cooperación": los nombres de los participantes, la firma de quien hizo los dibujos, la sobreposición de retazos de tela o de imágenes que responde a los diversos gustos de quienes participaron en la producción; todos estos elementos son parte del producto final (ver imagen 2). La presencia de estos rasgos, en suma, define una "estética" característica de las banderas -asociada a la yuxtaposición de materiales, imágenes, frases y nombres como proceso compositivo-, que es en buena medida el resultado del patrón colectivo de elaboración de las mismas.

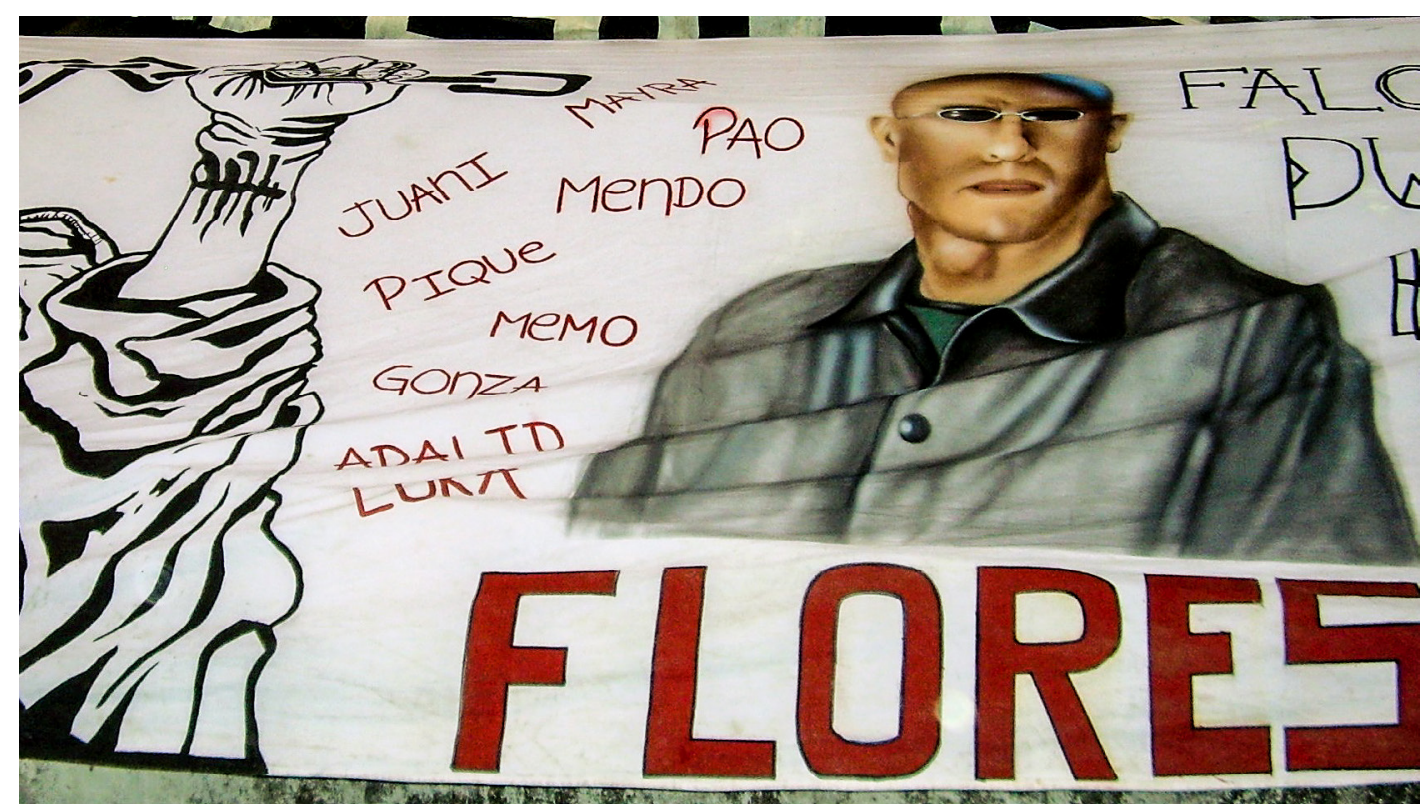

Imagen 2. Bandera con las firmadas de sus dueños. (Salta, 2009). Fotografía del autor.

\section{LAS BANDERAS Y LA ORGANIZACIÓN DE LOS VIAJES}

La elaboración de las banderas también incluye, generalmente, la organización de los viajes para exhibirlas. En esta tarea se advierte el mismo tipo de competencias organizativas que observamos al momento de la confección de las banderas. Un entrevistado de La Plata me decía al respecto:

Somos cinco, seis pibes en el barrio, que juntamos la guita entre todos, pusimos un poquito cada uno, hasta que compramos la tela, y una vez que compramos la tela se la llevamos a la tía de un amigo que fue la que la cosió. Un mes más o menos nos llevó en total hacerla.

\section{¿Y la plata como la juntaron?}

Hicimos una rifa, la rifa de una torta para juntar unos mangos... y después la mayoría de los pibes trabajamos, así que pusimos 50 pesos cada uno, y así juntamos la plata. 


\section{¿Y cómo hicieron para traerla [a Salta]?}

Sacamos un colectivo... el [señala a un amigo] fue el que se organizó más para sacar el colectivo: éramos como diez pibes, todos del barrio -allá está el tío de él, por ejemplo, el padrino de mi nena, y un par de familiares, y otro conocido- (...).

\section{$\dot{¿}$ Ustedes contratan el micro, el chofer, todo?}

Claro. Esta vez contratamos un micro que después nos bajó el dedo porque nos quiso cobrar más caro... y después no conseguíamos otro micro que tuviera capacidad para nosotros, los diez juntos, y entonces conocimos unos pibes, de Berazategui y contratamos un micro juntos. Ahora somos 50 en total. Es que sí o sí viajábamos todos juntos. Es más, para venir acá, iba a prender fuego el auto. En serio te digo. Iba a poner el auto como forma de pago para venir acá... algo que me costó tres años para comprármelo, y yo iba a pagar el micro con el auto mío, para venir todos juntos. Pero bueno, por suerte nos salió el micro, tenía 20 asientos así que pudimos (...). Y el viaje estuvo espectacular.

Como vemos tras el relato, el carácter colaborativo de las producciones estéticas se replica como patrón de organización para asistir a los recitales. Los mismos se han realizado en diversos puntos del país (Córdoba, San Juan, Salta, Tandil, Junín, Mendoza y La Plata han sido los sitios elegidos por Solari para realizar sus recitales), conduciendo esto a que los fans deban realizar largos viajes desde sus lugares de origen para asistir. En consecuencia, los seguidores se organizan para alquilar un colectivo, en el cual viajar el grupo de amigos y la gente del barrio. Incluso en algunos casos quien organiza el viaje y se encarga de la contratación del servicio puede obtener una pequeña ganancia que le sirve para comprar la entrada al show o algún consumo durante el o los días de estadía en el lugar donde se realiza el espectáculo; pero en todo caso estas operaciones no tiene un fin directo de lucro. Se trata más bien de asegurarse la presencia en el lugar, poder viajar acompañados de sus amigos o parientes, y vivir la experiencia del "viaje" colectivo como algo que forma parte, también, de aquello de lo que se va a apreciar.

Sin embargo, existen también emprendimientos más organizados y orientados por fines de lucro, que se promocionan en diversos lugares y ofrecen servicios adicionales ("remera de regalo", "credencial de recuerdo", "asado a la llegada", "CD con fotos", "pago en cuotas”, etcétera). En páginas como mundo redondo y redonditos de abajo, se asigna un espacio para la publicación de estos viajes organizados, que dan cuenta hasta qué punto se ha convencionalizado la escena. A su vez, en estas páginas se suben mapas del lugar donde se llevará a cabo el recital, información sobre accesos a los lugares, sitios para alojarse y diversas noticias sobre la producción del evento que pueden resultar útiles para planificar el viaje.

A su vez, involucrarse en estas actividades y canalizar recursos materiales de presupuestos familiares generalmente ajustados, implica decisiones que deben ser consensuadas con el grupo familiar. En este sentido, en los relatos sobre las posibilidades de asistencia a los recitales se advierte el anclaje de las elecciones de "gasto" y usos del dinero dentro de alternativas teñidas de sentidos morales. En esta clave, un joven aficionado refiere: "Yo fui a Córdoba y no fui a San Luis porque no tenía la plata para ir, no llegaba con la plata... O sea, sí llegaba, pero si voy es un gasto. Yo tengo mi familia, tengo mi nena, y bueno, cuando puedo me voy, pero sino tengo que pensar en mi familia también". ¿Vivir "una experiencia única" asistiendo al show o contribuir a la economía familiar? ¿Usar el dinero para esa "aventura” o reservarlo para comprar bienes "útiles”-zapatillas, teléfonos celulares-?. Estas decisiones suelen estar reguladas por la aprobación familiar y por una gestión colectiva de los recursos. De modo que las formas en que se organiza la "escena" del recital, también dependen entonces de esta "economía moral" (Thompson, 
1984 $)^{10}$ que, en base al hecho de reconocer como propias ciertas obligaciones sociales y valores morales (un sentido de la responsabilidad por "sustentar" económicamente el hogar o contribuir a ello, por ejemplo), regula la capacidad de asistencia y el sostenimiento de la adhesión.

La forma que adopta la escena, en suma, es producto de la estabilización de esta relación entre público, artista, y el conjunto de mediaciones que intervienen entre ellos y los constituyen como tales: recursos disponibles, patrones de organización, horizontes de expectativas, moralidades, etc. En este sentido, como señala Hennion, "no hay una frontera nítida entre la producción de contenidos y los modos de consumo: desde el momento en que el artista anticipa una constricción, atraviesa esta frontera" (Hennion 2002: 141). Así, la experiencia extraordinaria del recital se construye como un viaje épico, a la luz de un esfuerzo previo sostenido a base de "privaciones" y organización familiar y barrial, que promueve la construcción de ese carácter "extraordinario" de la situación de recital. En ese tránsito entre la trama de "privaciones" y el viaje como experiencia trascendente, las banderas se vuelven también la objetivación del "esfuerzo" puesto en seguir al artista, y plasmar las peripecias y la dedicación depositada en llevar la esfera cotidiana al momento extraordinario del recital. "Disfruto de mi enfermedad en manos de tu música" se lee en una bandera, y el entrevistado me explica: "porque hay que estar enfermo para hacer el viaje que hicimos".

\section{LA MÚSICA: UN REFUGIO PERSONAL COTIDIANO, VUELTO RITUAL COLECTIVO}

De modo que las banderas, como objeto-práctica, permiten mediar entre dos momentos de la experiencia de los fans: el ámbito cotidiano de la afición anclada en la esfera de lo privado, de un lado, y la presentación en esa dimensión extraordinaria de la vida de los fans que es el recital, de otro. En este tránsito, en torno a las banderas se plasma un actor colectivo (los grupos de aficionados, la propia "comunidad" de gusto). Pero la experiencia de vinculación (Hennion 2010) con esta música, en buena parte de las situaciones de escucha cotidianas de estos fans, es una experiencia personal y reflexiva.

En busca de tematizar esta dimensión, autores como Hennion (2012) y Benzecry (2012b), proponen la metáfora del adicto como un modo de dar cuenta de ese compromiso cotidiano con la música, por el cual se desarrollan una serie específica de aptitudes que permiten "dejarse llevar" por ella. Estos autores identifican algunas características de este tipo de escucha comprometida que se replican en estos fans: su carácter físico, su orientación hacia la "disolución del yo" en el momento del goce; o su sentido de inevitabilidad como práctica cotidiana, dirigida a la desconexión de los asuntos cotidianos. En nuestro caso, encontramos buena parte de esos modos de sostener la afición cotidiana: la escucha redundante, compulsiva, centrada en determinados pasajes, enmarcada en un sistema de preparaciones que conducen a la producción de un estado deseado. Este modo de vivir la afición y mantener un vínculo cotidiano con esta música es registrado y plasmado profusamente luego en las banderas, a partir de seleccionar determinados fragmentos de las líricas. Presento algunos ejemplos de frases empleadas: "Patricio Rey y sus

10 Entendemos aquí el concepto de economía moral de Thompson (1984) en un sentido amplio, como implicando un conjunto de valores que movilizan sentidos compartidos. Asimismo, con dicho concepto se procura dar cuenta de una dimensión particular que permite iluminar: mostrar cómo los comportamientos económicos asociados con la posibilidad de participación en la escena en estos aficionados, se regulan y organizan en el marco de valores morales compartidos. 
Redonditos de Ricota: te cura o te mata!"; "Amor letal”; "Una enfermedad de la que no quiero curarme"; "Ladrón de mi cerebro"; "No debí decirlo: ahora tu esclavo soy yo"; "Te quiero tanto que me hace daño"; "Disfruto de mi enfermedad en manos de tu música".

Las frases son elocuentes por sí mismas. Las alusiones a la enfermedad, la cura y la adicción son recurrentes. La escucha como una obsesión que implica ambiguamente tanto una "cura" como un "daño"11 y conduce a "perderse" subjetivamente en el objeto: "ladrón de mi cerebro", "ahora tu esclavo soy yo", expresiones que dan cuenta de la intensidad con que es vivenciada la afición. Este tipo de vinculación, lleva a que estos fans olviden o procesen sus problemas cotidianos: "estoy yo y la música, y ya no me importa más nada” (Diego) "La música genera eso, me lleva a varios lados" (Leandro). Ese ejercicio de escucha, cabe subrayar, suele modularse en un sentido específico, que adopta la forma de un refugio subjetivo de las circunstancias en las que los aficionados se ven inmersos. Se trata de una dimensión que también es captada en las banderas, en expresiones como "tu música es el territorio donde nada nos hace daño"12, o la muy frecuente "el único héroe en este lio".

De modo que las banderas, en esta trama, se vuelven no solo objetivación del "esfuerzo" puesto en seguir al artista y plasmar la dedicación depositada en llevar la esfera cotidiana al momento extraordinario del recital, sino una manera de procesar colectivamente una experiencia subjetiva personal, asociada a la música como recurso para constituir un espacio propio, de protección y amparo frente a las incertidumbres de la vida. Del mismo modo que lo ha señalado Jenkis (1992) para diversas prácticas fans, el mundo de estos fanáticos se configura como un "mundo entre fronteras", que toma tanto referencias de la cultura de masas como de la vida cotidiana, y construye su propia identidad en esa zona. Entre la referencia a la "comunidad" de gusto y las formas de inscripción de la experiencia cotidiana, se configura un universo de prácticas sustentado por los fans, en los que estos se comprometen, elaboran sentidos de pertenencia a partir de compartir una afición y, a la vez que "hacen arte", procesan colectivamente diversas pruebas existenciales.

\section{REFLEXIONES FINALES}

Una mirada a las prácticas de ritualización desde el recital puede remitirnos a una visión del mismo como un momento de -en términos durkheimianos- efervescencia colectiva y contacto con los fundamentos de la socialidad. Pero esto encubre toda una cadena de mediaciones que intervienen en la producción de lo inmediato. En el recorrido presentado abordamos el conjunto de acciones y prácticas que los fanáticos movilizan para sostener esa escena y "producir" la festividad. Desde esta perspectiva, la noción benjaminiana de ritual y de "aura" (Benjamin 1982) como momento de abstracción ritual y como posibilidad de una experiencia absoluta, requiere ser relativizada, dando lugar al análisis de los modos en los que los propios sujetos definen y redefinen (en el incesante "trabajo de la mediación", en términos de Hennion) su relación con

11 Benzecry observa para el caso de los aficionados a la Opera: "el carácter físico de la adicción a la música a veces adquiere una forma dual que combina sentirse enfermo y sentirse curado” (2012: 200).

12 La frase, inscripta en una bandera, curiosamente, no corresponde a Los Redondos ni a ninguno de sus integrantes. Se trata de la adaptación de una frase adjudicada a Andrés Calamaro: "La música es el territorio en el que nada nos hace daño". En la canción Música Lenta, a su vez, Calamaro canta: "La música lenta es un lugar donde nada nos puede hacer mal". 
los objetos artísticos y el "culto" hacia ellos. ${ }^{13}$ Como advertimos, la escena ritual se conecta con otros espacios sociales, se extiende temporalmente más allá del momento del recital, e involucra a un conjunto más vasto de personas que aquellos que estrictamente asisten a los shows. En este sentido, al observar las banderas desde el ángulo de su "producción", se nos ilumina un repertorio de acciones que se prolongan más allá de los bordes de cada evento, y que visibiliza toda una red de colaboradores que hacen posible, a su vez, sostener la pasión y la presencia.

Asimismo, describimos la práctica de producción de banderas como una práctica regulada, en la cual intervienen una serie de convenciones sobre que incluir en una bandera, como usarla, y sobre la actividad de su apreciación (la existencia de un público que considere valioso y motivo de "reconocimiento" ese trabajo). Pero además de ello, existe una red de colaboración colectiva que hace posible esa "presentación pública", anclada en la vida cotidiana de los seguidores, que se vale de conocimientos sobre técnicas, usos y criterios estéticos, que generalmente no son percibidos como tales pero que son movilizados para lo obtención del objeto final. Así, se cuenta con un conjunto de competencias organizativas, saberes técnicos y "personal de apoyo" que, por un lado, habilitan este tipo de producciones estéticas, pero por otro las constriñen como proyectos estéticos más elaborados. Las dificultades materiales impiden la utilización de materiales específicos, lleva a las personas a buscar medios alternativos para obtener resultados similares, y contribuyen a configurar una "economía moral" de sostenimiento de la escena basada en su "extraordinariedad" y en el sacrificio personal.

En este sentido, seguir un objeto-práctica en las relaciones en las que se conecta y constituye, nos ha conducido a registrar la constitución de un "mundo del arte" en torno a la música. Desde este punto de vista, las banderas funcionan no sólo como emblema grupal (Aliano et al, 2010) presentado en la escena del recital ante la "comunidad de gusto", sino como actividad colectiva: objeto que es resultado de un entramado de acción y organización que la hace posible. Así, la bandera - producción colectiva, es luego la bandera - emblema en el recital; y por último, cerrando el círculo que re-conduce a la dimensión cotidiana de la experiencia, la bandera se torna reliquia, que pasa a formar parte de una "textura diferencial sagrada" (Martín, 2006) en ese mundo cotidiano. Se completa el circuito en torno a un objeto, que es un entramado de sentidos, saberes, materialidades y relaciones. Restituir esa circularidad, en suma, nos ha permitido visibilizar los procesos de creación colectiva que la sustentan y mostrar algunos de sus sentidos políticos y sus efectos sociales.

El caso nos ha mostrado que la constitución de una serie de convenciones en torno a la afición ha conducido a constituir un "mundo de arte" propio (y que ello no es sinónimo de "profesionalización" de estas prácticas). La elaboración de estas banderas ha vuelto a sus hacedores verdaderos artífices de objetos estéticos en sí mismos, y con ello de todo un mundo de arte popular, que dialoga con otro mundo profesionalizado en torno a la música que escuchan. Iluminar ese dialogo nos acerca a una concepción más compleja -y democratizante- de los procesos de creación artística, y al modo en el que "arte" y "sociedad" se imbrican de modos concretos, en prácticas concretas y contextos precisos. En esta clave, al tiempo que estos fans

13 Martin Jay (2009) ha señalado las bases antropológicas de la teoría de la mimesis en Benjamin (la antropología de Spencer, Taylor y Frazer con su creencia en una mentalidad primitiva mimética) y la necesidad de una revisión de estos supuestos criticados por la antropología contemporánea (2009: 390). En un sentido similar a la observación de Jay, advertimos que cierta noción de "ritual" implícita en Benjamin -que encuentra en el ritual la fuente original de la mayor parte de las formas expresivas de la vida cultural-, merece cierta reconsideración a la luz de algunos debates contemporáneos. 
devienen "artistas", elaboran colectivamente las respuestas a sus inquietudes, sus incertidumbres y sus pruebas personales.

\section{REFERENCIAS BIBLIOGRÁFICAS}

Alabarces, Pablo. 2008. "Introducción. Un itinerario y algunas apuestas", en: P. Alabarces y M. G. Rodríguez (comps.), Resistencias y mediaciones. Estudios sobre cultura popular. Buenos Aires: Paidós.

Aliano, Nicolás. 2015. Música, afición y subjetividad entre seguidores del Indio Solari. Un estudio sobre procesos de individuación en sectores populares, Tesis de doctorado en Ciencias Sociales, FaHCE, Universidad Nacional de La Plata.

. 2018. "La dimensión terapéutica de la experiencia musical: aflicción y trabajo reflexivo en jóvenes fans de un cantante argentino". Revista Latinoamericana de Ciencias Sociales, niñez y juventud, 16 (1).

Aliano, N., Lopez, M., Pinedo, J., Stefoni, A., Welschinger, N. 2010. “'Banderas en tu corazón'. Narrativas identitarias, vida cotidiana y prácticas de apropiación de la música rock en los sectores populares contemporáneos", Cuestiones de Sociología. Revista de Estudios Sociales, 6.

Becker, Howard. 2008. Los mundos del arte. Sociología del trabajo artístico. Bernal: Universidad Nacional de Quilmes.

.2009. "El poder de la inercia", Apuntes de investigación del CECYP, No 15.

Bell, Catherine. 1992. Ritual Theory, Ritual Practice. New York: Oxford UniversiyPress. 1997. Ritual: Perpectives and Dimensions. New York: Oxford Universiy Press.

Benedetti, Cecilia. 2008. "El rock de los desangelados. Música, sectores populares y procesos de consumo". Trans. Revista Transcultural de Música, 12.

Benjamin, Walter. 1982. "La obra de arte en la época de su reproductibilidad técnica", en: Discursos interrumpidos I. Madrid: Taurus.

Benzecry, Claudio. 2012a. "Introducción. Cultura. Instrucciones de uso", en: C. Benzacry (comp.), Hacia una nueva sociología cultural. Mapas, dramas, actos y prácticas. Bernal: Universidad Nacional de Quilmes.

.2012b. El fanático de la ópera. Etnografía de una obsesión, Buenos Aires: Siglo XXI.

Blazquez, Gustavo. 2009. Músicos, mujeres y algo para tomar. El mundo de los cuartetos de Córdoba, Ciudad de Córdoba, Ediciones Recovecos

Borda, Libertad. 2011. Bettymaniacos, Luzmarianas y Mompirris: el fanatismo en los foros de telenovelas latinoamericanas, Tesis de doctorado en Ciencias de la Sociales, Facultad de Ciencias Sociales, UBA.

Cardoso Filho, Jorge y Xavier de Oliveira, Luciana. 2013. "Espaço de experiência e horizonte de expectativas como categorias metodológicas para o estudo das cenas musicais". Trans. Revista Transcultural de Música, 17.

Da Matta, Roberto. 2002. Carnavales, malandros y héroes. Hacia una sociología del dilema brasileño, México D. F: Fondo de Cultura Económica.

Díaz, María Cecilia. 2019. "Historias detrás de objetos: organizadores y vendedores en un circuito de eventos". Vibrant: Virtual Brazilian Anthropology, 16

Hennion, Antoine. 2002. La pasión musical, Barcelona: Paidós. 2010. "Gustos musicales: de una sociología de la mediación a una pragmática del gusto". Comunicar, 17 (34) 
. 2012. "Melomanos: el gusto como performance", en: C. Benzacry (comp.), Hacia una nueva sociología cultural. Mapas, dramas, actos y prácticas. Bernal: Universidad Nacional de Quilmes.

Jauss, Hans. 1992. Experiencia estética y hermenéutica literaria. Madrid: Taurus.

Jay, Martin. 2009. Cantos de experiencia. Variaciones modernas sobre un tema universal. Buenos Aires: Paidós.

Jenkins, Henry. 2010. Piratas de textos. Fans, cultura participativa y televisión, Paidós, Barcelona. Koselleck, Reinhart. 1993. Futuro pasado: para una semántica de los tiempos históricos. Barcelona: Paidós.

Martín, Eloisa. 2006. No me arrepiento de este amor. Um estudo etnográfico das prácticas de sacralizacao de uma cantora argentina. Tesis de doctorado para el doctorado en el Museo Nacional, Universidad Federal de Rio de Janeiro.

Peirano, Mariza. 2000. "A Análise Antropológica de Rituais". Serie Antropología \#270. Departamento de Antropología. Universidade de Brasilia. Mimeo.

Salerno, Daniel y Silba, Malvina. 2006. "Juventud, identidad y experiencia: las construcciones identitarias populares urbanas". Revista Question 10: 1-10. (https://perio.unlp.edu.ar/ojs/ index.php/question/article/view/211)

Semán, Pablo. 2006. "El pentecostalismo y el 'rock chabón' en la transformación de la cultura popular”, en: D. Míguez y P. Semán (eds.), Entre santos, cumbias y piquetes. Las culturas populares en la Argentina reciente. Buenos Aires: Biblos.

Thompson, Edward P. 1984. Tradición, revuelta y consciencia de clase. Estudios sobre la crisis de la sociedad preindustrial, Barcelona: Editorial Crítica.

\title{
FANS, RItUALS AND ART WORLDS: AN ANALYSIS OF A PROCESS OF POPUlar Collective CREATION
}

\begin{abstract}
As part of an investigation about fans of a popular Argentine musician, the article analyzes a specific dimension of one of his practices. The inquiry explores the production of flags by the public, to be presented at the performances of this artist. In this sense, reconstructing the uses of an object - the flags - leads us to the collaborative network within which it is constituted, making visible a popular "art world" around music. It is a collective network "behind the scenes" that makes them possible as aesthetic objects: a scene anchored in the everyday world of people (and that is why it uses the resources, knowledge and relationships available in that world), which at the same time is co-produced in interaction with the ritual moment of the performance, being fundamental to sustain it as such. To make these popular "flag makers" visible aims to illuminate a scarcely discussed analytical possibility: it presents a popular "art world" not sustained in formal institutions, but rather in a network of informal collective practices and a moral economy that makes its continuity possible. The case, consequently, opens a path to deepen the analysis of the processes of collective artistic creation in the popular world, and underlines the social effects of these practices on the fans' experience.
\end{abstract}

Keywords: popular art, collaborative networks, music fans, ritual practices, collective artistic creation

Data recibido: 2019-09-01

Data aceptado: 2020-02-13 